ORIGINAL ARTICLE

\title{
Increased mortality odds ratio of male liver cancer in a community contaminated by chlorinated hydrocarbons in groundwater
}

\author{
L J-H Lee, C-W Chung, Y-C Ma, G-S Wang, P-C Chen, Y-H Hwang, J-D Wang
}

See end of article for authors' affiliations

Correspondence to: Professor J-D Wang Institute of Occupational Medicine and Industrial Hygiene, National Taiwan University College of Public Health, No. 1, Section 1, Jen-Ai Road, Taipei,

Taiwan 100. jdwang@ha.mc.ntu.edu.tw

Accepted 3 September 2002

\begin{abstract}
Aims: To investigate the association between cancer mortality risk and exposure to chlorinated hydrocarbons in groundwater of a downstream community near a contaminated site.

Methods: Death certificates inclusive for the years 1966-97 were collected from two villages in the vicinity of an electronics factory operated between 1970 and 1992. These two villages were classified into the downstream (exposed) village and the upstream (unexposed) according to groundwater flow direction. Exposure classification was validated by the contaminant levels in 49 residential wells measured with gas chromatography/mass spectrometry. Mortality odds ratios (MORs) for cancer were calculated with cardiovascular-cerebrovascular diseases as the reference diseases. Multiple logistic regressions were performed to estimate the effects of exposure and period after adjustment for age. Results: Increased MORs were observed among males for all cancer, and liver cancer for the periods after 10 years of latency, namely, 1980-89, and 1990-97. Adjusted MOR for male liver cancer was $2.57(95 \%$ confidence interval 1.21 to 5.46$)$ with a significant linear trend for the period effect.

Conclusion: The results suggest a link between exposure to chlorinated hydrocarbons and male liver cancer risk. However, the conclusion is limited by lack of individual information on groundwater exposure and potential confounding factors.
\end{abstract}

$\mathrm{H}$ azardous waste sites have emerged as a major environmental health concern in many countries. ${ }^{1}$ In Taiwan, for instance, more than 160 illegal waste dumpsites were identified by the Environmental Protection Administration (Taiwan EPA). ${ }^{2}$ In 1994, the Taiwan EPA declared a hazardous waste site in Taoyuan County. This site, designated as the R site, was a former electronics factory, which began its operation after 1970 and closed in 1992. Previous site investigations revealed that soil and groundwater in the $\mathrm{R}$ factory were contaminated by chlorinated hydrocarbons more than 10 years ago. ${ }^{3}$ An on-site source area was identified with soil concentration up to $1100 \mathrm{mg} / \mathrm{kg}$ of tetrachloroethylene. ${ }^{34}$ Moreover, the contamination (which included tetrachloroethylene, trichloroethylene, cis-1,2-dichloroethylene, 1,1dichloroethylene, vinyl chloride, 1,1,1-trichloroethane, 1,1dichloroethane, and 1,2-dichloroethane) had spread to the offsite groundwater downstream of the factory. ${ }^{56}$ Trichloroethylene (TCE) and tetrachloroethylene (PCE) were the most frequently detected chemicals with concentrations up to 930 and $4800 \mu \mathrm{g} / \mathrm{l},{ }^{6}$ much higher than the maximum contaminant level (MCL) of $5 \mu \mathrm{g} / \mathrm{l}$ set by the US Environmental Protection Agency (EPA). ${ }^{7}$ TCE and PCE, metal cleaning solvents widely used in the electronics industry, have hepatic and renal toxicity, and have been classified as group $2 \mathrm{~A}$ carcinogens by the International Agency for Research on Cancer (IARC). ${ }^{8}$ They were shown to induce liver and kidney cancer in animal bioassays, but there was limited evidence of carcinogenicity in humans from epidemiological studies. ${ }^{9}{ }^{10}$

As the zoning policy for industrial area was not strictly enforced in the 1970s and 1980s, there was no clear boundary between factories and communities in Taiwan. There were about 10000 community residents living in the village downstream of the R factory in the late 1990s. Many residents living in the vicinity of $\mathrm{R}$ factory relied mainly on groundwater locally extracted from residential wells for their primary domestic water supply. In 1994, the pollution was brought to light, and then tap water was provided to these nearby house- holds. Potential health risk from chronic exposure to the contaminated groundwater was a major concern to the local residents. We therefore conducted this study to determine if there is any association between cancer mortality and residence in a downstream community contaminated with chlorinated hydrocarbons in contrast with a neighbouring upstream village.

\section{METHODS}

\section{Groundwater sampling and analysis}

We conducted groundwater sampling from off-site residential wells in the nearby communities for exposure assessment from October 1999 to May 2000. According to the local groundwater hydrogeology, the off-site groundwater flow direction was generally towards the north and northeast in the first aquifer. ${ }^{11}$ Thus, we had a door to door survey on the residential wells, which were available in the nearby communities. The $\mathrm{R}$ factory is located in the downstream village, which is separated from the upstream village by the Provincial Route No. 1. For the downstream area to the north of the Route and northeast of the factory, 44 wells were identified and 69 groundwater samples were collected. For the upstream community, only two wells to the south of the factory were available for collecting two water samples. Another three wells in the western side of the factory (about 750 metres away) in the downstream village were also sampled to explore the extent of contamination. In total, we had 74 groundwater samples to describe contaminant concentrations surrounding

Abbreviations: $\mathrm{CB}$, cerebrovascular; $\mathrm{CV}$, cardiovascular; $\mathrm{HbsAg}$ hepatitis B surface antigen; IARC, International Agency for Research on Cancer; $M C L$, maximum contaminant level; $M O R$, mortality odds ratio; $\mathrm{PCE}$, tetrachloroethylene; TCE, trichloroethylene; VOC, volatile organic compound 


\begin{tabular}{|c|c|c|c|c|c|c|c|}
\hline \multirow[b]{3}{*}{ Chemicals } & \multirow[b]{3}{*}{$\begin{array}{l}\text { Carcinogenicity } \\
\text { IARC group }\end{array}$} & \multicolumn{4}{|c|}{ Downstream area (to the north of the Route No. 1 and the factory) } & \multirow{2}{*}{\multicolumn{2}{|c|}{$\begin{array}{l}\text { Upstream area } \\
\begin{array}{l}\text { Well water concentration } \\
(n=2)\end{array}\end{array}$}} \\
\hline & & \multicolumn{2}{|c|}{ Well water concentration $(n=44)$} & \multicolumn{2}{|c|}{$\begin{array}{l}\text { Estimated lifetime average } \\
\text { daily intake† for } \\
\text { carcinogens (mg/kg/day) }\end{array}$} & & \\
\hline & & Median (range) $(\mu \mathrm{g} / \mathrm{l})$ & $\begin{array}{l}\text { Percentage } \\
\text { above MCL* }\end{array}$ & $\begin{array}{l}\text { Reasonable } \\
\text { maximal } \\
\text { exposure }\end{array}$ & $\begin{array}{l}\text { Average } \\
\text { exposure }\end{array}$ & $\begin{array}{l}\text { Median } \\
\text { (range) ( } \mu \mathrm{g} / \mathrm{l})\end{array}$ & $\begin{array}{l}\text { Percentage } \\
\text { above MCL }\end{array}$ \\
\hline Vinyl chloride & 1 & 0.003 (ND-72.3) & $29.5 \%$ & 4.22E-04 & $3.64 \mathrm{E}-07$ & ND & 0 \\
\hline Tetrachloroethylene & $2 \mathrm{~A}$ & 2.95 (ND-5228.3) & $45.5 \%$ & 4.45E-02 & $2.89 \mathrm{E}-05$ & 0.05 (ND-0.1) & 0 \\
\hline Trichloroethylene & $2 \mathrm{~A}$ & 28.43 (ND-1790.7) & $65.9 \%$ & $1.96 \mathrm{E}-02$ & $1.62 \mathrm{E}-04$ & $0.1(0.1-0.1)$ & 0 \\
\hline 1,1-dichloroethylene & 3 & 1.35 (ND-1240.4) & $27.3 \%$ & & & ND & 0 \\
\hline 1,1,1-trichloroethane & 3 & 0.67 (ND-1504.4) & $11.4 \%$ & & & ND & 0 \\
\hline cis-1,2-dichloroethylene & NA & 3.05 (ND-1376.0) & $15.9 \%$ & & & ND & 0 \\
\hline 1,1-dichloroethane & NA & 1.81 (ND-227.9) & NA & & & 0.05 (ND-0.1) & NA \\
\hline
\end{tabular}

NA, not available in International Agency of Research on Cancer (IARC) or US EPA; ND, not detected.

* Maximum contaminant level (MCL) is the national drinking water standard set by US EPA.?

†Lifetime average daily intake was defined as the exposure dose per unit body weight and per day, averaged over 70 years from inhalation and dermal absorption based on residents' exposure scenarios..$^{13}$

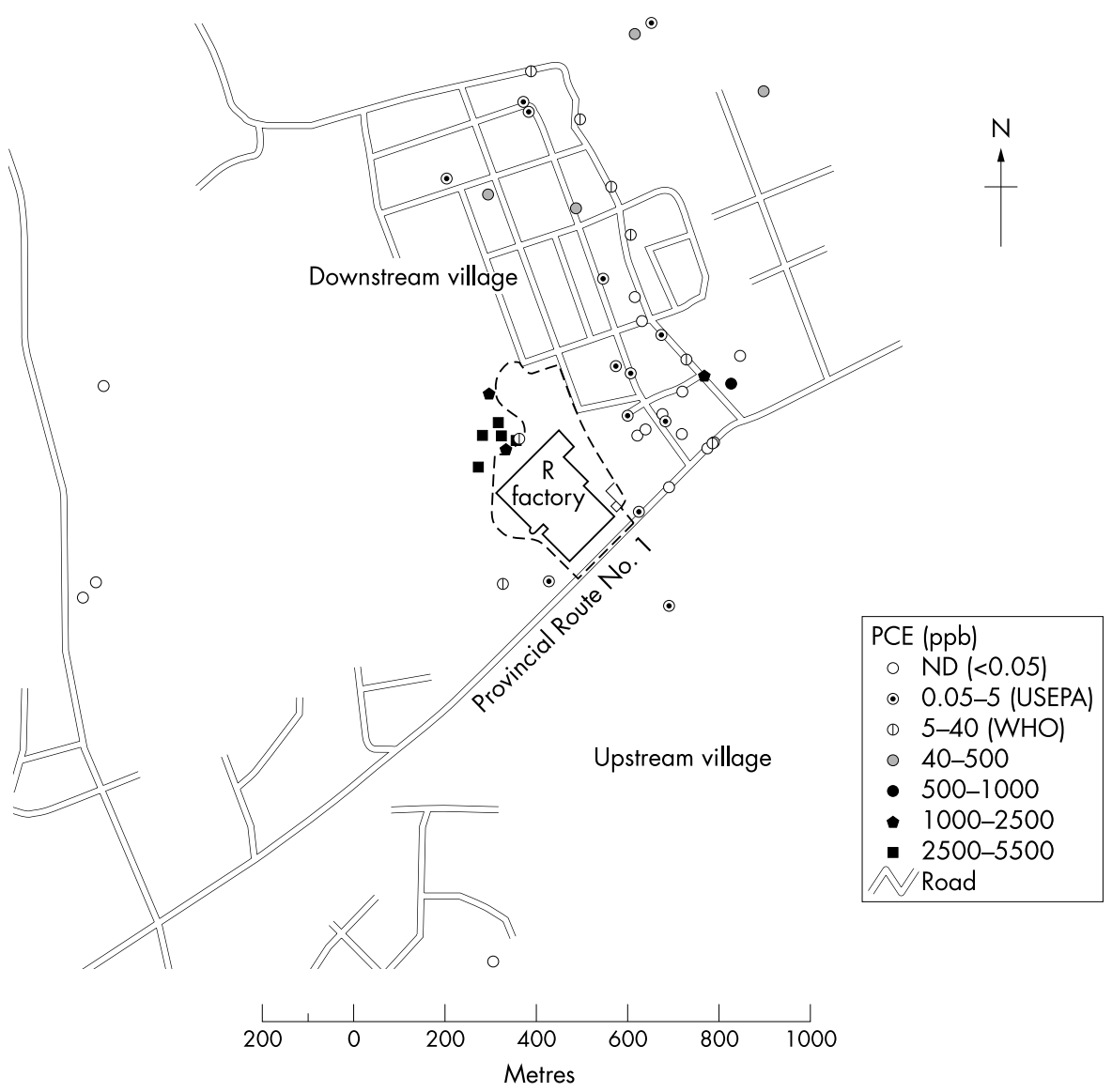

Figure 1 Geographical distribution of 49 residential wells near the $R$ factory and levels of PCE in the groundwater.

the hazardous site. The concentrations of 19 chlorinated volatile organic compounds (VOCs) were determined using a method modified from the US EPA method 524.2. ${ }^{12}$ The procedures of sampling, analysis, and quality control were described in detail elsewhere. ${ }^{13}$

\section{Epidemiological investigation}

Death certificates inclusive for the years 1966-97 were collected from the local household registration offices in the two villages adjacent to the R factory. Data obtained from the death certificate were identification (ID) number, gender, age, date of birth/death, address, and causes of death. Without any prior knowledge of exposure, an independent team of nosolo- gists in a tertiary care teaching hospital was responsible to code the underlying cause of death according to the ninth revision of the International Classification of Diseases (ICD9).${ }^{14}$ Any case with cancer recorded as an underlying cause of death or as an "other significant condition" was counted as a case of cancer. Furthermore, to improve the accuracy of being coded as cancer, all decedents were ascertained through linkage with Taiwan's National Cancer Registry using ID number.

We conducted this study using mortality odds ratio (MOR) design, which can be regarded as a variant of a case-control study. ${ }^{15}{ }^{16}$ The location of residence recorded on the death certificate was used for determination of exposure status of each decedent. The exposed cases are the downstream decedents 
Table 2 MOR with 95\% confidence intervals $(\mathrm{Cl})$ of deaths from liver cancer in contrast with CV-CB and non-cancer diseases controlling for age

\begin{tabular}{|c|c|c|c|c|c|c|c|c|c|c|}
\hline \multirow[b]{2}{*}{ Gender } & \multirow[b]{2}{*}{ Cause of death } & \multicolumn{3}{|c|}{ 1966-79 } & \multicolumn{3}{|c|}{ 1980-89 } & \multicolumn{3}{|c|}{ 1990-97 } \\
\hline & & $E(+)$ & $E(-)$ & MOR $\ddagger(95 \% \mathrm{Cl})$ & $E(+)$ & $E(-)$ & MOR $(95 \% \mathrm{Cl})$ & $E(+)$ & $E(-)$ & MOR $(95 \% \mathrm{Cl})$ \\
\hline \multirow[t]{3}{*}{ Male† } & Liver cancer & 3 & 3 & $0.82(0.15$ to 4.44$)$ & 13 & 6 & $3.19(0.99$ to 10.32$)$ & 10 & 7 & $3.34(1.00$ to 11.13$)$ \\
\hline & CV-CB diseases* & 30 & 22 & & 25 & 36 & & 19 & 34 & \\
\hline & Non-cancer diseases & 104 & 56 & $0.59(0.12$ to 2.88$)$ & 104 & 86 & 1.78 (0.64 to 4.94$)$ & 67 & 97 & $2.33(0.84$ to 6.50$)$ \\
\hline \multirow[t]{3}{*}{ Female } & Liver cancer & 0 & 1 & - $\quad$ r ton & 1 & 2 & 1.02 & 3 & 2 & 2.09 (0.35 to 12.59$)$ \\
\hline & CV-CB diseases* & 25 & 18 & & 28 & 21 & & 13 & 15 & \\
\hline & Non-cancer diseases & 53 & 40 & - & 62 & 41 & $0.64(0.06$ to 6.56$)$ & 45 & 45 & $1.96(0.33$ to 11.50$)$ \\
\hline
\end{tabular}

$E(+)$, downstream village; $E(-)$, upstream village.

*CV-CB (cardiovasular-cerebrovascular diseases) as reference disease include ICD-9 codes 390-398, 401-405, 410-414, 420-425, 428-429, 430-438.

†Cochran-Armitage test revealed significant linear trend for calendar periods in the downstream village with $p$ values of 0.02 and 0.01 in contrast with $\mathrm{CV}-\mathrm{CB}$ and non-cancer deaths, respectively.

$\ddagger$ Mantel-Haenzel summary odds ratio were calculated after controlling for three age groups.

Table 3 MOR $(95 \% \mathrm{Cl})$ for cancer in men stratified by residential area and time period after adjustment for age

\begin{tabular}{|c|c|c|c|c|c|}
\hline \multirow[b]{2}{*}{ Cause of death (ICD-9) } & \multicolumn{2}{|c|}{ Residential area } & \multicolumn{3}{|c|}{ Period of death } \\
\hline & $\begin{array}{l}\text { Upstream } \\
\text { village }\end{array}$ & Downstream village & 1966-79 & 1980-89 & 1990-97 \\
\hline All cancer (140-208) & 1 & 2.07 (1.31 to 3.27 ) & 1 & 1.93 (1.08 to 3.46$)$ & 2.26 (1.24 to 4.13$)$ \\
\hline Liver cancer (155) & 1 & 2.57 (1.21 to 5.46$)$ & 1 & 3.96 (1.36 to 11.51$)$ & 4.17 (1.41 to 12.38 ) \\
\hline Stomach cancer (151) & 1 & $2.18(0.97$ to 4.89$)$ & 1 & $1.43(0.52$ to 6.87$)$ & 1.66 (0.59 to 4.69$)$ \\
\hline Colorectal cancer (153-154) & 1 & $0.83(0.24$ to 2.89$)$ & 1 & 0.64 (0.12 to 3.28$)$ & $1.24(0.29$ to 5.30$)$ \\
\hline Lung cancer (162) & 1 & 1.75 (0.79 to 3.89$)$ & 1 & 3.66 (1.12 to 11.96$)$ & 3.01 (0.87 to 10.46 ) \\
\hline
\end{tabular}

with cancer, while the unexposed cases are the upstream decedents with cancer. The criteria for selecting appropriate controls or reference diseases included: (a) no causal association between reference diseases and exposure; and (b) comparable mortality of reference diseases between the exposed and unexposed populations. ${ }^{17}$ We deliberately considered cardiovascular and cerebrovascular (CV-CB) diseases as the reference diseases because deaths from CV-CB diseases were aetiologically unrelated to chlorinated hydrocarbons according to literature review. ${ }^{18}{ }^{19}$ However, acute occupational exposure to high levels of chlorinated solvents might induce cardiac arrhythmia. ${ }^{10}$ Therefore, CV-CB diseases, excluding arrhythmia related deaths (ICD-9 codes 426-427), were selected as the reference diseases. An alternative approach was to consider all non-cancer diseases as the reference diseases or controls, which was also performed to test the hypothesis.

The exposure classification was verified with the measured contaminant concentrations in residential wells of the nearby communities. The upstream and downstream villages are separated by the Provincial Route No. 1, which gives people from both villages equal access to the nearby Taoyuan Municipal Hospital (which has 600 beds) about 3-6 km away. In other words, differential migration related to health care between these two villages was unlikely. We considered residents' occupational exposure by identifying previous employees in the R factory through linkage with the database of the Labor Insurance Bureau. We also reanalysed the data after excluding these workers from decedents.

As the slow release of contaminants probably resulted from dumping since the establishment of the R factory in 1970, we stratified the calendar periods into 1966-79, 1980-89, and 1990-97, to examine the effect of time period. To allow for 10 years to detect health effects from the exposure, the first decade, 1966-79, could be regarded as the historical control period. Age was grouped into $<30,30-49,50-69$, and $>70$ years. The decedents aged below 30 were excluded because no appropriate reference disease could apply in this age group and they were only 19 cancer deaths in total.

\section{Statistical analysis}

MORs were calculated for cancer during each period after stratifying by gender and age group. Summary odds ratios were computed after controlling for age, to estimate the relative risk for periods with the Mantel-Haenszel method ${ }^{20}$ The Cochran-Armitage test for trend was applied to examine the effect of time period for both downstream and upstream villages. ${ }^{21}$ Multiple logistic regressions were performed to evaluate the exposure effect after adjustment for age and period. Data analyses were performed with the use of SAS software. ${ }^{22}$

\section{RESULTS}

Figure 1 illustrates the geographic distribution of 49 residential wells. There was significant spatial variation in groundwater concentrations as shown by an example result of PCE. Table l summarises frequency distribution of contaminant concentrations in the residential wells. PCE concentrations above the MCL of $5 \mu \mathrm{g} / \mathrm{l}$ were found in 20 of 44 (45.5\%) downstream wells. The highest concentrations of contaminants were found in the wells closest to the R factory. In contrast, chlorinated hydrocarbons were either at trace level or not detected in the upstream wells. The background data in the upstream village could therefore provide a valid evidence of non-exposure, which corroborated our study design of using the upstream village as the unexposed community.

A total of 1333 decedents in the two villages were identified during the study period 1966-97. Among them we found 266 cancer deaths: 254 were recorded on the death certificates; 12 died of other competitive causes and were identified by linkage with the National Cancer Registry Database. Leading causes of cancer deaths were cancer of the liver $(n=53)$, stomach $(\mathrm{n}=39)$, colon and rectum $(\mathrm{n}=26)$, and lung $(\mathrm{n}=41)$, while cardiovascular-cerebrovascular diseases accounted for 344 deaths.

There was no increase of MOR for cancer of any site during the historical control period 1966-79. Table 2 summarises the 
Table 4 Comparison of sociodemographic characteristics between exposed and unexposed villages according to census survey in 1980 and 1990

\begin{tabular}{|c|c|c|c|c|c|c|}
\hline \multirow[b]{2}{*}{ Parameters } & \multicolumn{3}{|c|}{1980 census } & \multicolumn{3}{|c|}{1990 census } \\
\hline & $E(+)$ & $E(-)$ & $\mathrm{p}\left(\chi^{2}\right.$ test $)$ & $E(+)$ & $E(-)$ & $\mathrm{p}\left(\chi^{2}\right.$ test $)$ \\
\hline Population (numbers of residents) & 11647 & 10282 & - & 9282 & 13084 & - \\
\hline Gender $(\%)$ & & & NS & & & NS \\
\hline Male & 52.55 & 51.64 & & 50.40 & 50.98 & \\
\hline Female & 47.45 & 48.36 & & 49.60 & 49.02 & \\
\hline Marriage (\%) & 38.81 & 39.56 & NS & 43.01 & 42.04 & NS \\
\hline Age $(\%)$ & & & NS & & & NS \\
\hline Young people (aged below 14) & 38.41 & 38.12 & & 32.05 & 33.11 & \\
\hline Adult (aged 15-64) & 59.39 & 59.91 & & 64.03 & 62.56 & \\
\hline Old people (aged over 65) & 2.20 & 1.97 & & 3.92 & 4.33 & \\
\hline$\%$ educated above college level & 6.00 & 4.18 & $<0.01$ & 10.92 & 6.75 & $<0.01$ \\
\hline$\%$ employed & 57.51 & 57.28 & NS & 53.58 & 54.22 & \\
\hline Occupation (\%) & & & $<0.01$ & & & $<0.01$ \\
\hline Agriculture, fishery & 7.98 & 7.49 & & 7.19 & 6.85 & \\
\hline White collar* & 33.26 & 28.72 & & 34.55 & 28.66 & \\
\hline Blue collart & 50.18 & 55.86 & & 50.33 & 56.35 & \\
\hline
\end{tabular}

results of MOR for liver cancer among males and females in contrast with CV-CB and all non-cancer diseases. MORs after a 10 year latency were significantly elevated in men, but not in women. The summary MOR for male liver cancer during 1990-97 was increased with an OR (95\% CI) of 3.34 ( 1.00 to 11.13). In the downstream village, there was a statistically significant linear trend for the period effect using either CV-CB or non-cancer deaths as reference diseases, but in the upstream village no such a trend was found by the Cochran-Armitage test. Multiple logistic regression revealed that MOR for male liver cancer was 2.57 (95\% CI 1.21 to 5.46) after adjustment for age and period, as shown in table 3. In addition, the effect of time period was significant for liver cancer as well as all cancer combined. After excluding previous workers of the R factory from the decedents, we found that the result was almost the same because there were only three deaths of liver cancer and 21 non-cancer deaths.

\section{DISCUSSION}

Our study showed that residence at a groundwater contaminated community was significantly associated with male liver cancer when age, latency period, and occupational exposure in the $\mathrm{R}$ factory were taken into consideration. This statistical association, however, does not necessarily indicate a true causal relation. To our knowledge, this is the first environmental epidemiological study to find an increased liver cancer risk in a community population potentially exposed to mixtures of volatile chlorinated hydrocarbons in groundwater. Few community based studies could find a link between cancer risk and dumping of hazardous wastes. ${ }^{1}$ Nevertheless, there was clearer evidence of the association between liver cancer and TCE from occupationally based cohort and case-control studies. ${ }^{23}$ Thus, we must carefully consider potential confounders and examine the limitations before making conclusions.

First, selection bias was one of the major concerns in the case-control study. We carefully excluded diseases that might be associated with exposure to chlorinated hydrocarbons and finally decided to select CV-CB diseases as the reference diseases to ensure the validity of MOR analysis. Furthermore, we used the census data in 1980 and 1990 to estimate CV-CB mortality rates for assessing the comparability between the exposed and unexposed villages. The result showed approximately 1.25-fold higher CV-CB mortality rates for males aged over 50 in the upstream village than those living downstream.
Based on this finding, we might overestimate our MORs by about $25 \%$. Such a magnitude, however, could not totally explain the 2.6-fold increase of MOR for male liver cancer. In addition, as non-cancer deaths were chosen as an alternative reference disease, MOR for liver cancer still showed a statistically significant trend for the period effect in the downstream village.

Second, individuals might be substantially misclassified because exposure status for the decedents was determined at group level by the place of residence. We deliberately selected an upstream neighbouring village as the unexposed population, which was validated by chemical analysis of groundwater samples. Neighbouring communities tend to share relatively similar socioeconomic characteristics, which may result in a similar pattern of mortality except for diseases associated with the exposure. Table 4 reveals such comparability between the exposed and unexposed villages from the population census data in 1980 and 1990. Although quite similar, people in the downstream village had a slightly higher proportion of high education as well as of white collar workers, and therefore appeared less likely to be exposed to occupational carcinogens in their work environments. Furthermore, if non-differential misclassification of exposure exists, the use of residential area as a surrogate measure will most likely decrease the sensitivity of our study to detect a significant effect.

Third, studies based on mortality records would likely underestimate cancer occurrence because of the longer latency compared with incidence data. To minimise the above effect, we matched the ID of each decedent with the National Cancer Registry and found 12 additional cases of cancer which died of other competitive causes. Thus, our study should be more comprehensive and the estimates of MOR were more accurate than other studies with only mortality data.

Fourth, we must evaluate the possibility of other aetiological agents of liver cancer, including hepatitis B and C viruses, alcohol consumption, smoking, arsenic, aflatoxins, etc. ${ }^{24}$ Unfortunately, limited data on death certificates usually precluded us from adjustments for these potential confounders with statistical models. Nevertheless, we attempted to validate our findings by examining available historical health related aggregate data. A seroprevalence survey in 1984 showed that hepatitis B surface antigen (HBsAg) carrier rate was $16.4 \%$ in Taoyuan City, which contained the exposed village; and $10.5 \%$ in the upstream Pate City, which contained 
the unexposed village. ${ }^{25}$ If hepatitis B carriers were homogeneously distributed in different villages of the two cities, then hepatitis B could attribute a relative risk around 1.17-1.51 for the exposed village, assuming hepatitis B infected persons were about 5-98 times more likely to develop liver cancer. ${ }^{26-28}$ The estimated effect of hepatitis B therefore could not totally explain the magnitude of the increased risk. We checked the data of cigarette and alcohol sales in 1975 from the Taiwan Provincial Cigarette and Alcohol Monopoly Bureau. It showed that the cigarette and alcohol consumption rates for Taoyuan City were 79.8 packs and $2.42 \mathrm{ml}$ per person per year respectively, while those for Pate City were 65.8 packs and $2.36 \mathrm{ml}$ per person per year, respectively. None of the wells in the study area were contaminated by arsenic according to a previous investigation..$^{25}$ In addition, it was unlikely that there would be a differential pattern of food consumption involving aflatoxin contamination between the nearby communities. Thus, the argument based on these aggregate data could not completely refute the association between male liver cancer and living downstream.

We deliberately used the calendar periods of death to classify potential exposure durations into 1966-79, 1980-89, and 1990-97, although detailed individual information on amount of groundwater consumption and duration of residence was not available. Most of these chlorinated hydrocarbons migrated through soils to groundwater, and spread downstream gradually because of physical properties of dense non-aqueous phase liquids. ${ }^{29}$ An estimated amount of 3000 gallons PCE per year were used in the factory until 1985. Degradation processes might produce a series of transformed products, such as TCE, dichloroethylene, and vinyl chloride, through the anaerobic reductive dehalogenation. ${ }^{30}$ With a rate of about $0.24 \mathrm{~m} /$ day, the first-zone groundwater flowed towards the downstream area. ${ }^{11}$ Thus, a 10 year period was taken as the duration between disposal of chlorinated solvents and potential health effects from exposure to contaminated groundwater in the downstream community. Although an occupational cohort study conducted by Anttila et al revealed increased risk of liver cancer in the follow up period $\geqslant 20$ years, ${ }^{31}$ the potential synergistic effects from chronic hepatitis $\mathrm{B}$ infection and mixed exposure to chlorinated hydrocarbons made us allow for only 10 year latency. A significant linear trend for the period effect corroborated our hypothesis of a 10 year latency for the increased mortality on liver cancer.

Recently a risk assessment was conducted on the downstream residents to estimate cancer risks based on reasonable maximal exposure for vinyl chloride, PCE, and TCE, which were $8.4 \times 10^{-6}, 1.9 \times 10^{-4}$, and $1.4 \times 10^{-4}$, respectively. ${ }^{13}$ Table 1 shows the estimates of lifetime exposure doses for IARC 1 and $2 \mathrm{~A}$ chemicals based on the exposure scenarios of inhalation and dermal absorption while showering and washing with contaminated water at home. These estimates did not account for volatile contaminants from boiling water or household activities and should be regarded as a lower bound of true residential exposure. The major target organs based on animal bioassays include the liver, ${ }^{8-10}$ which supports our MOR findings. In addition, it is also possible that chemical hepatocarcinogens may cause synergistic effect on hepatitis B carriers, which were shown on alcohol ${ }^{32}$ and aflatoxin. ${ }^{33}$

Increased MORs of liver cancer were found only in males, but not in females. Epidemiological studies have consistently shown that males were about 2-4 times more likely to develop liver cancer than females, ${ }^{24}{ }^{34}$ including in Taiwan. ${ }^{35}$ The HBsAg carrier rates in males were slightly higher than those in females $(12.2 \% v 9.2 \%)$ in Taiwan. ${ }^{36}$ It seems that hepatitis B infection alone might not totally explain such a difference in gender. As many investigators pointed out that there was a higher proportion of alcohol drinking, ${ }^{32}$ and exposure to occupational carcinogens among males, ${ }^{37}{ }^{38}$ these exposures might be synergistic factors with chronic hepatitis B infection for hepatocarcinogenesis. We wondered whether a similar mech-

\section{Main message}

- This is the first epidemiological study to suggest a link between exposure to chlorinated hydrocarbons contaminated in groundwater and increased risk of male liver cancer.

\section{Policy implication}

- Chlorinated solvents were difficult to eliminate from the contaminated groundwater. Proper precautions should be taken in the life cycle of a product's manufacturing for prevention of environmental pollution and diseases.

anism from chlorinated hydrocarbons in a hepatitis B endemic area might also contribute to this gender discrepancy. Further studies are warranted to falsify such a hypothesis.

\section{Conclusion}

This study shows how the method of MOR may be applied to investigate environmental diseases. The results suggest a link between chlorinated hydrocarbons contaminated in groundwater and increased risk of male liver cancer. However, the causal inference is limited by the lack of individual information on the exposure dose and many potential confounding factors. One should be cautious in interpreting the estimates of MOR, which are usually more useful for hypothesis generation than hypothesis testing.

\section{ACKNOWLEDGEMENTS}

We thank Drs Wen-Chung Lee, Kai-Shen Liu, and Yi Sun for commenting on the manuscript. We are also grateful to colleagues in the Department of Medical Records, for their excellent work on coding the death certificates. This study was supported in part by the Taiwan Environmental Protection Administration, ROC (EPA-88-G1-0403-405). Lukas J-H Lee is a recipient of the NHRI MD-PhD and DDSPhD Predoctoral Fellowship (RE89M003C).

Authors' affiliations

L J-H Lee, C-W Chung, P-C Chen, Y-H Hwang, J-D Wang, Institute of Occupational Medicine and Industrial Hygiene, College of Public Health, National Taiwan University

Y-C Ma, G-S Wang, Institute of Environmental Health, College of Public Health, National Taiwan University

\section{REFERENCES}

1 Vrijheid $M$. Health effects of residence near hazardous waste landfill sites: a review of epidemiologic literature. Environ Health Perspect 2000:108/suppl 1):101-12.

2 Taiwan Environmental Protection Administration. Environmental policy monthly. Volume II, Issue 11, May 1999. Available: http://www.epa.gov.tw/english/epm/issue9905.htm [accessed 31 August 2001].

3 Bechtel Environmental, Inc. Preliminary site investigation report. Taoyuan site, Taiwan, Republic of China. San Francisco, CA: Bechtel Environmental, Inc., 1995

4 Target Environmental Services, Inc. Soil gas/perched groundwater/soil survey. Taoyuan site, Taiwan. Columbia, MD: Target Environmental Services, Inc., 1995.

5 Industrial Technology Research Institute. Project report of sampling and analysis of residential wells near the Taoyuan Site [in Chinese]. Hsinchu, Taiwan: Union Chemical Laboratory, ITRI, 1994

6 Geomatrix Consultants, Inc. Revised health assessment. Taoyuan and Chupei Sites, Taiwan, Republic of China. San Francisco, CA: Geomatrix Consultants Inc., 1995.

7 US Environmental Protection Agency. National Primary Drinking Water Regulations. EPA/810/F-94/001. 1999. Available: http://www.epa.gov/safewater/consumer/mcl.pdf [accessed 15 February 1999].

8 International Agency for Research on Cancer. IARC monographs on the evaluation of carcinogenic risks to humans. Vol 63. Dry cleaning, some chlorinated solvents and other industrial chemicals. Lyon: IARC, 1995.

9 Agency for Toxic Substances and Disease Registry. Toxicological profile for trichloroethylene. Atlanta, GA: ATSDR, 1997 
10 Agency for Toxic Substances and Disease Registry. Toxicological profile for tetrachloroethylene. Atlanta, GA: ATSDR, 1997.

11 Geomatrix Consultants, Inc. Groundwater remediation technical practicability evaluation report. Taoyuan site, Taiwan. San Francisco, CA: Geomatrix Consultants Inc., 1998.

12 US Environmental Protection Agency. Measurement of purgeable organic compounds in water by capillary column gas chromatography/ mass spectrometry. Revision 4.0, Method 524. Environmental Monitoring System Laboratory, Cincinnati, 1992

13 Lee LJH, Chan CC, Chung CW et al. Health risk assessment on residents exposed to chlorinated hydrocarbons contaminated in groundwater of a hazardous waste site. J Toxicol Environ Health $A$ 2002;65:219-35.

14 World Health Organisation. International classification of diseases, 9th revision. Geneva: WHO, 1985

15 Miettinen OS, Wang JD. An alternative to the proportionate mortality ratio. Am J Epidemiol 1981;114:144-8.

16 Rothman KJ, Greenland S. Modern epidemiology, 2nd edn. Philadelphia, PA: Lippincott-Raven, 1998:76-7.

17 Wang JD, Miettinen OS. The mortality odds ratio (MOR) in occupational mortality studies - selection of reference occupation(s) and references causes of death. Ann Acad Med (Singapore) 1984;13:312-16.

18 Kristensen TS. Cardiovascular diseases and the work environment. A critical review of the epidemiologic literature on chemical factors. Scand J Work Environ Health 1989;15:245-64.

19 White RF, Proctor SP. Solvents and neurotoxicity. Lancet 1997;349: 1239-43

20 Breslow NE, Day NE. Statistical methods in cancer research. Vol 1. The analysis of case-control studies. Lyon: International Agency for Research on Cancer, 1980:220-59.

21 Stokes ME, Davis CS, Koch GG. Categorical data analysis using the SAS system, 2nd edn. Cary, NC: SAS Institute Inc., 2000.

22 SAS Institute Inc. SAS/STAT User's Guide, release 6.04. Cary, NC: SAS Institute Inc., 1989

23 Wartenberg D, Reyner D, Scott CS. Trichloroethylene and cancer: epidemiologic evidence. Environ Health Perspect 2000;108/suppl 2): 161-76.

24 Lodon WL, McGlynn KA. Liver cancer. In: Schottenfield D, Fraumeni JF, eds. Cancer epidemiology and prevention, 2nd edn. New York: Oxford University Press, 1996:772-93.
25 Cai SF. Ecological correlation study on major risk factors of various malignant neoplasms in Taiwan; 1972-1983. Master thesis. Institute of Public Health, National Taiwan University [in Chinese].

26 International Agency for Research on Cancer. IARC monographs on the evaluation of carcinogenic risks to humans. Vol 59. Hepatitis viruses. Lyon: IARC, 1994.

27 Beasley RP, Hwang LY, Lin CC, et al. Hepatocellular carcinoma and hepatitis B virus. A prospective study of 22707 men in Taiwan. Lancet 1981;2:1129-33.

28 Beasley RP. Hepatitis B virus: the major etiology of hepatocellular carcinoma. Cancer 1988;61:1941-56.

29 Huling SG, Weaver JW. Dense nonaqueous phase liquids. EPA/540/4-91/002, Robert S. Kerr Environmental Research Laboratory, US EPA, Ada, OK, 1991.

30 Sims JL, Suflita JM, Russell HH. Reductive dehalogenation of organic contaminants in soil and ground water. EPA/540/4-90/054, Robert S. Kerr Environmental Research Laboratory, US EPA, Ada, OK, 1991.

31 Anttila A, Pukkala E, Sallmen M, et al. Cancer incidence among Finnish workers exposed to halogenated hydrocarbons. J Occup Environ Med 1995:37:797-806.

32 Chen CJ, Liang KY, Chang AS, et al. Effects of hepatitis B virus, alcohol drinking, cigarette smoking and familial tendency on hepatocellular carcinoma. Hepatology 1991;13:398-406.

33 Wang LY, Hatch M, Chen CJ, et al. Aflatoxin exposure and risk of hepatocellular carcinoma in Taiwan. Int J Cancer 1996;67:620-5.

34 Chen CJ, Yu MW, Liaw YF. Epidemiological characteristics and risk factors of hepatocellular carcinoma. J Gastroenterol Hepatol 1997; 12:S294-308.

35 Lin TM, Tsu WT, Chen CJ. Mortality of hepatoma and cirrhosis of liver in Taiwan. Br J Cancer 1986:54:969-76.

36 Chen DS, Sung JL, Lai MY. A seroepidemiologic study of hepatitis B virus infection in Taiwan. J Formosan Med Assoc 1978;77:908-18.

37 Du CL, Wang JD. Increased morbidity odds ratio of primary liver cancer and cirrhosis of the liver among vinyl chloride monomer workers. Occup Environ Med 1998;55:528-32.

38 Farber E. Alcohol and other chemicals in the development of hepatocellular carcinoma. Clin Lab Med 1996;16:377-95. 